\title{
Conexões
}

Educação Física, Esporte e Saúde

\section{O tema da saúde na educação física escolar em três periódicos da educação física brasileira}

\author{
Victor José Machado de Oliveira ${ }^{1}$
}

\section{RESUMO}

Objetivo: Este estudo objetiva investigar a produção do conhecimento acerca do tema da saúde na Educação Física escolar. Métodos: A metodologia caracterizou-se pela natureza qualitativa e bibliométrica e por seu caráter documental e exploratório. Foi realizado um levantamento em três periódicos: Movimento; Revista Brasileira de Ciências do Esporte; Pensar a Prática. Resultados e Discussão: Verificou-se que o "peso" das publicações referentes ao tema investigado é tímido diante da demanda instaurada no cenário nacional. Conclusão: Há dois grandes movimentos dentro da produção analisada: 1) um reforça o entendimento de saúde orientado nas Ciências Naturais e Biológica; 2) outro, busca superar a concepção restrita (biológica) de saúde a partir das Ciências Sociais e Humanas. Por último ressalta-se a necessidade de ampliar o número de periódicos investigados a fim de prover novos dados e, assim, fortalecer o tema investigado.

Palavras-chave: Serviços de Saúde Escolar. Educação Física e Treinamento. Educação em Saúde.

\footnotetext{
${ }^{1}$ Universidade Federal do Espírito Santo, Centro de Educação Física e Desportos, Vitoria - ES, Brasil.
}

\section{Correspondência:}

Victor José Machado de Oliveira. Centro de Educação Física e Desportos, Universidade Federal do Espírito Santo, Av. Fernando Ferrari, 514, CEP 29075910, Goiabeiras, Vitória - ES, Email: oliveiravjm@gmail.com 


\section{Health theme in school physical education in three Brazilian physical education journals}

\section{ABSTRACT}

Objective: This study aimed to investigate the production of knowledge about the subject of health in school Physical Education. Methods: methodology was characterized by qualitative and bibliometric nature and by documental and exploratory research. The survey observed three journals: Movimento, Revista Brasileira de Ciências do Esporte, and Pensar a Prática. Results and Discussion: The research showed that the presence of publications related to the subject investigated is timid in the face of the demand established in national scenario. Conclusion: There are two major movements within the analyzed production: 1) one reinforces the understanding of health oriented in the Natural and Biological Sciences; 2) another seeks to overcome the limited conception (biological) health from the Social Sciences and Humanities. Finally, it emphasizes the need to expand the number of journals investigated in order to provide new data and thus strengthen the subject investigated.

Keywords: School Health Services. Physical Education and Training. Health Education.

\section{El tema salud en la educación física escolar en tres periódicos de la educación física brasileña}

\section{RESUMEN}

Objetivo: Este estudio tiene como objetivo investigar la producción del conocimiento acerca del tema de la salud en la Educación Física escolar. Metodología: La metodología se caracterizó por la naturaleza cualitativa y bibliométrica y por su carácter documental y exploratorio. Se realizó un levantamiento en tres periódicos: Movimento; Revista Brasileira de Ciências do Esporte; Pensar a Prática. Resultados y discusión: Se verificó que el "peso" de las publicaciones referentes al tema investigado es tímido ante la demanda instaurada en el escenario nacional. Conclusión: Hay, por lo general, dos grandes movimientos dentro de la producción analizada: 1) uno refuerza el entendimiento de salud orientado en las Ciencias Naturales y Biológicas; 2) otro, busca superar la concepción restringida (biológica) de salud a partir de las Ciencias Sociales y Humanas. Por último, se resalta la necesidad de ampliar el número de periódicos investigados a fin de proveer nuevos datos y así fortalecer el tema investigado.

Palabras Clave: Servicios de Salud Escolar. Educación y Entrenamiento Físico. Educación en Salud. 


\section{INTRODUÇÃO}

A saúde sempre teve uma forte relação com a Educação Física (EF) e, no caso brasileiro, sua instituição se deu fortemente a partir da década de 1970 quando se organizaram os primeiros laboratórios na área, inclusive os de fisiologia do exercício. Marca-se, então, um determinado tipo de saúde, qual seja, aquele orientado na biologia (CARVALHO, 2005). Na EF escolar, a saúde também é um tema presente, seja como um objeto e/ou objetivo principal ou secundário (OLIVEIRA, 2004).

Hodiernamente, é percebido o desenvolvimento de políticas e programas governamentais em torno do tema da promoção da saúde no ambiente escolar como, por exemplo, o Programa Saúde na Escola (PSE). O PSE foi instituído em 2007, através de uma parceria entre os Ministérios da Educação e da Saúde, imbuído em ações intersetoriais que buscam a melhoria da qualidade de vida da população brasileira (BRASIL, 2007; BRASIL, 2011). Essas iniciativas valorizam a saúde na escola em âmbito nacional e isso parece solicitar dos agentes escolares (assim, também, das disciplinas as quais representam) pensarem nas contribuições que podem dar em vista de fortalecer as ações de saúde nesse ambiente. Em estudo vinculado à temática, Oliveira, Martins e Bracht (2015a) discutem que apesar de a EF não ser citada diretamente nos documentos deste programa, há potenciais relações a serem desenvolvidas, apesar de um baixo nível de clareza dos profissionais da saúde e educação acerca do mesmo.

Destarte, compreendemos que perceber como se encontra a produção do conhecimento sobre tal temática nos permite analisar quais ideias são disseminadas pela literatura especializada da área - e se é possível, a partir delas, perceber possíveis contribuições da EF para fortalecer as ações de educação para a saúde no ambiente escolar. Esse esforço também se constitui uma prática de mapear e avaliar a área que têm aumentado nos últimos tempos (BRACHT et al., 2011). Assim, este estudo nos situa quanto ao volume e "peso" de publicações referentes à produção total de três periódicos científicos que veiculam estudos do campo da EF: Revista Movimento, Revista Brasileira de Ciências do Esporte e Revista Pensar a Prática. Não obstante, cremos que, de forma profícua, também é possível considerar quais concepções de saúde têm orientado essa produção, quais os autores, instituições, regiões de concentração da produção, etc. Dados qualitativos e bibliométricos que nos fornecerão uma primeira aproximação com esse objeto de estudo: a produção acadêmica brasileira acerca do tema da saúde na EF escolar.

De um modo geral, Carvalho (2005) nos indica que existe uma dimensão majoritária que orienta a produção do conhecimento na EF brasileira, que é o das Ciências Naturais e Biológica. Por outro lado, há um movimento que surge na década de 1980, em que os intelectuais da área se enveredam pelos caminhos 
das Ciências Sociais e Humanas, como, também, da Saúde Coletiva. Acreditamos na hipótese de que na produção referente ao tema da saúde na EF escolar, também encontraremos tal embate nas propostas e desenhos de estudos que se configuram nos artigos publicados nos periódicos investigados.

Antes de prosseguirmos, compreendemos ser importante delimitar nossa compreensão de saúde, já que ela nos possibilitará alçar/fundamentar nossas análises. Em princípio, nossa compreensão supera a concepção negativa de saúde enquanto "ausência de doença". Também se busca ressignificar a concepção ampliada da Organização Mundial da Saúde (OMS) que diz que a saúde é o "perfeito bem-estar físico, mental e social". Esse movimento de ressignificação está apoiado em autores como Dejours (1986) e Canguilhem (2009).

Dejours (1986), ao ressignificar o conceito da OMS indica que a saúde, para cada homem, mulher ou criança é possuir meios para traçar um caminho pessoal e original, em direção ao bem-estar. Segundo Lunardi (1999), esse autor infere a saúde em sua processualidade e não apenas como um fim. Assim, também, a caracteriza como uma questão ligada às pessoas. Para Canguilhem (2009, p. 77), "o que caracteriza a saúde é a possibilidade de ultrapassar a norma que define o normal momentâneo, a possibilidade de tolerar infrações à norma habitual e de instituir normas novas em situações novas". Essa concepção também nos permite compreender a saúde das pessoas a partir das próprias pessoas que são capazes de instituir suas próprias normas de vida, ou seja, possuem o poder de se tornarem normativas de si mesmas.

Em Canguilhem (2009), percebemos a saúde como uma construção subjetiva, a qual se relaciona à experiência pessoal.

Achamos que a vida de qualquer ser vivo, mesmo que seja uma ameba, não reconhece as categorias de saúde e doença a não ser no plano da experiência, que é, em primeiro lugar, provação no sentido afetivo do termo, e não no plano da ciência. A ciência explica a experiência, mas nem por isso a anula (CANGUILHEM, 2009, p. 78).

Cabe ressaltar que a experiência que se dá a nível pessoal, também é perpassada pela esfera social - que lhe confere sentidos e significados mediante as ações das pessoas que se relacionam em um coletivo. Nessas relações é ressaltada a função da ciência, porém, em uma postura mais humilde (o que nem sempre é adotada, devido às orientações político-epistemológicas vinculadas a uma concepção hegemônica de ciência²).

\footnotetext{
2 Para maiores informações sobre o assunto ver Santos (2010). Nesta obra, o autor evidencia o paradigma hegemônico que se orienta a partir das Ciências Naturais e está pautado nos princípios positivistas, na neutralidade sujeito/objeto, na relação causa-efeito, etc.
} 
Em síntese reflexiva sobre as concepções de Dejours (1986) e de Canguilhem (2009), Lunardi (1999, p. 39) aponta que as definições de saúde desses autores:

[...] apontam-nos alternativas e permitem-nos sair de um vínculo próprio do poder pastoral, entre o pastor e o rebanho. A saúde, nestas concepções, já não se refere aos especialistas, às autoridades, a um padre, a um médico, a uma enfermeira, [ou a um professor de EF] senão a cada um de nós como sujeitos da nossa saúde (inserto nosso).

Essas considerações permitem (pelo menos do ponto de vista teórico) que os sujeitos sejam empoderados com relação à constituição da sua saúde. Contudo, cabe ressaltar que os profissionais da saúde e da educação não estão excluídos desse processo. O que ocorre é a descentralização da saúde, que passa a ser uma questão coletiva. Tais premissas corroboram a construção de uma proposta de educação para a saúde que vise o coletivo dos sujeitos que constituem o ambiente escolar. Por isso, condescendemos com a posição de que, para a EF escolar, a saúde é uma questão pedagógica (BRACHT, 2013). Ou seja, não cabe utilizar esse tempo-espaço para promoção apenas da saúde biológica (leia-se aptidão física), mas para promover meios para que os alunos se tornem sujeitos de sua própria saúde.

Acreditamos que essa revisão conceitual nos permitirá melhor compreender nosso objeto escolhido para esse texto. Assim, elegemos como objetivo deste estudo: investigar a produção do conhecimento acerca do tema da saúde na EF escolar e analisar suas perspectivas teórico-metodológicas, tanto quanto os indicadores bibliométricos acerca dessa produção.

\section{Estratégias Metodológicas}

Este estudo se caracteriza pela natureza qualitativa e bibliométrica e por seu caráter documental e exploratório (GIL, 2008). Trata-se de um levantamento dos artigos relacionados ao tema da saúde na EF escolar nos periódicos: Revista Movimento (Movimento); Revista Brasileira de Ciências do Esporte (RBCE); Revista Pensar a Prática (Pensar a Prática). Optamos por estas revistas, pois compreendermos que são veículos de socialização das produções provenientes da EF escolar e que, nesse caso, poderíamos acessar as produções específicas sobre nosso objeto de estudo.

A Movimento 3 é uma publicação científica da Escola de Educação Física da Universidade Federal do Rio Grande do Sul, fundada em 1994, e que publica

\footnotetext{
${ }^{3}$ Sítio eletrônico: http://www.seer.ufrgs.br/Movimento.
} 
artigos relacionados ao campo da EF em interface com as Ciências Humanas e Sociais - em específico, nos aspectos pedagógicos, históricos, políticos e culturais. Possui conceito Qualis-Capes A2 em Educação Física e Educação.

A $\mathrm{RBCE}^{4}$ é uma publicação do Colégio Brasileiro de Ciências do Esporte (CBCE), fundada em 1979, que publica, trimestralmente, artigos sobre as temáticas que compõe a área de Educação Física/Ciências do Esporte e que espelhem a grande diversidade e variedade teórico-metodológica. Possui conceito Qualis-Capes B1 em Educação Física.

A Pensar a Prática $^{5}$ é um periódico editado pela Faculdade de Educação Física da Universidade Federal de Goiás, fundado em 1998, e publica artigos relacionados ao campo acadêmico/profissional da Educação Física/Ciências do Esporte com enfoque nos temas da cultura corporal e do movimento humano sob diversas matrizes teórico-metodológicas - educação, sociologia, filosofia, psicologia, biomecânica, nutrição, fisiologia, arte, etc. Possui conceito QualisCapes B2 em Educação Física.

Foram consultadas as versões online das revistas acima especificadas em busca de artigos que se relacionassem com nosso objeto de estudo. O recorte temporal foi do primeiro número do ano de fundação de cada revista até o último número do ano de 2015. Foram eliminados da investigação os volumes da RBCE referentes aos Anais do Congresso Brasileiro de Ciências do Esporte, os volumes que apresentaram "link corrompido" (v. 4, n. 2 de 1983 - v. 6, n. 2 de 1985 - v. 12 , n. 1 de 1992 - v. 15 , n. 2 de 1994 - v. 20, n. 2-3 de 1999) e o v. 18, n. 3 de 1997 que só apresentou o editorial.

Num primeiro momento, recorremos aos sumários das revistas em busca pelos títulos que se aproximassem do tema da saúde de uma forma geral e da saúde na EF. Desse primeiro levantamento, observamos a presença de 34 (trinta e quatro) artigos na Movimento, 50 (cinquenta) artigos na RBCE e 16 (dezesseis) artigos na Pensar a Prática - um somatório de 100 (cem) artigos.

Num segundo momento, após leitura dos resumos, procedemos a triagem desses 100 artigos selecionando aqueles que tematizassem a saúde na EF escolar. Nesse levantamento obtivemos 8 (oito) artigos na Movimento, 11 (onze) artigos na RBCE e 2 (dois) artigos na Pensar a Prática - total de 21 (vinte e um) artigos.

A partir desse segundo levantamento, analisamos os 21 artigos selecionados de forma mais particular realizando leitura completa dos mesmos. Observamos na dimensão bibliométrica a relação com o percentual total de

\footnotetext{
${ }^{4}$ Sítio eletrônico: http://rbceonline.org.br/revista/index.php/RBCE/index.

${ }^{5}$ Sítio eletrônico: http://www.revistas.ufg.br/index.php/fef.
} 
publicação por ano, número de autores, tipologia dos artigos de acordo com as políticas de seções das revistas, titulação, região e instituição dos autores. Na análise qualitativa observamos as orientações teórico-metodológicas dos estudos, suas principais discussões e conclusões. Na sequência passaremos a apresentação e análise dos dados produzidos.

\section{A FACE BIBLIOMÉTRICA DAS ANÁLISES}

Um primeiro ponto que alçamos análise já se encontra no quantitativo de artigos referentes ao tema da saúde na EF. De 100 incidências nas três revistas, apenas $21 \%$ se vincularam ao tema da saúde na EF escolar. Buscamos entender tal fenômeno a partir de Bracht et al. (2011), Manoel e Carvalho (2011) e Kirk (2010) quando sinalizam a atrofia dos estudos referentes à subárea pedagógica da EF tanto no Brasil (quanto nos EUA) - o que parece ser, também aqui, o caso específico do tema investigado. As fortes pressões político-epistemológicas dos órgãos de fomento à pesquisa e da Grande Área da Saúde tem acometido aquilo que Manoel e Carvalho (2011) denominam de "biodinamização" da produção do conhecimento em EF. Ou seja, parece haver uma crescente produção na subárea da biodinâmica (orientada nos estudos biofisiológicos), em detrimento das subáreas sociocultural e pedagógica.

Quando comparamos o número total de artigos de cada revista, desde sua gênese até o presente, com as produções com o tema saúde na EF escolar, percebemos como é tímido (ou quase inexpressivo) o "peso" (volume) dessas publicações. A primeira ocorrência da temática investigada foi em 1990 na RBCE, na Movimento foi no ano de 1996 e na Pensar a Prática somente em 2005. A relação "artigos totais publicados/artigos sobre a saúde na escola" foi: Movimento - 680/8 (1,2\%); RBCE - 1.115/11 (1\%); Pensar a Prática - 524/2 $(0,4 \%)$. Em números gerais, somando-se os artigos das três revistas, temos a relação de $2.319 / 21$, ou seja, um volume de $0,9 \%$ do total de artigos publicados nas respectivas revistas.

Se comparados com os artigos do primeiro levantamento (saúde na EF) a amostra referente à saúde na EF escolar já apresenta uma pequena parcela ( $21 \%)$, essa expressão é drasticamente reduzida para menos de $1 \%$ quando em comparação com os artigos totais publicados nas revistas. Esse é um dado crítico, pois mediante a demanda social vigente em torno do tema da saúde na escola (e da participação da EF nesse processo), os poucos artigos publicados é um marco que demonstra uma baixíssima acumulação de conhecimentos em torno dessa temática.

Em relação ao número total de autores, $48 \%$ dos estudos publicados nas três revistas foram assinados por somente um(a) autor(a) e, conforme o número 
de autores que assinam os textos aumentam, diminuem-se o percentual de artigos: 2 autores (24\%); 3 autores (19\%); 4 autores (10\%).

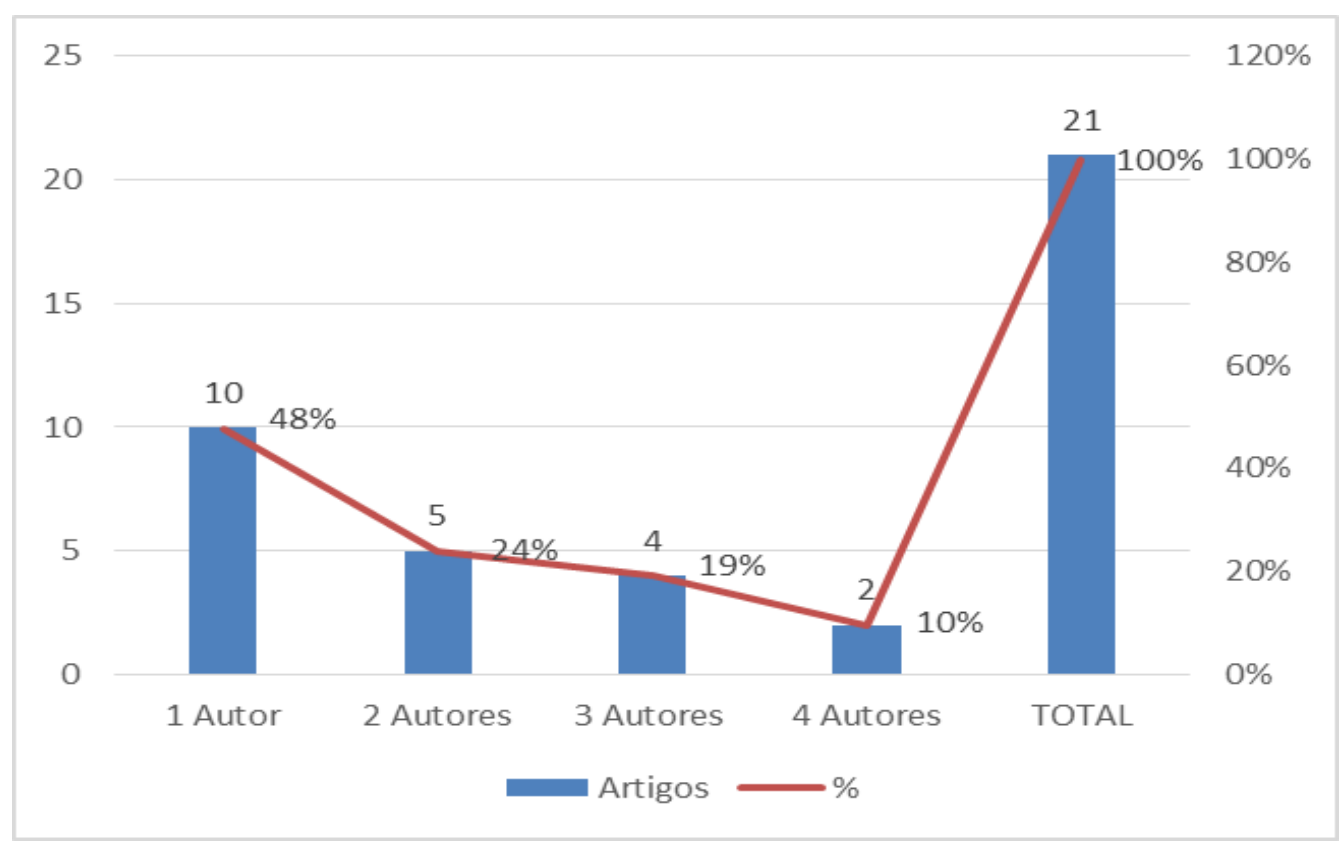

Figura 1 - Número total de autores que assinaram os artigos por revista.

Fonte: Movimento; RBCE; Pensar a Prática

Esse número é distribuído e melhor visualizado na tabela 1, onde a Movimento apresentou o maior percentual de artigos assinados por somente um autor (75\%). Na RBCE esse número ficou dividido entre um e dois autores (ambos com 36\%, cada um). A Pensar a Prática só apresentou dois artigos em que três autores assinaram (100\%).

Tabela 1 - Número de autores que assinaram os artigos por revista

\begin{tabular}{ccccccccc}
$\begin{array}{c}\text { Número de } \\
\text { Autores }\end{array}$ & $\begin{array}{c}\text { Artigos } \\
\text { Movimento }\end{array}$ & $\begin{array}{c}\% \\
\text { (M) }\end{array}$ & $\begin{array}{c}\text { Artigos } \\
\text { RBCE }\end{array}$ & $\begin{array}{c}\% \\
\text { (RBCE) }\end{array}$ & $\begin{array}{c}\text { Artigos } \\
\text { Pensar } \\
a\end{array}$ & $\begin{array}{c}\% \\
\text { Prática }\end{array}$ & Total & $\begin{array}{c}\% \\
\text { (Total) }\end{array}$ \\
\hline Autor & 6 & $75 \%$ & 4 & $36 \%$ & 0 & $0 \%$ & 10 & $48 \%$ \\
\hline Autores & 1 & $13 \%$ & 4 & $36 \%$ & 0 & $0 \%$ & 5 & $24 \%$ \\
\hline 3 Autores & 0 & $0 \%$ & 2 & $18 \%$ & 2 & $100 \%$ & 4 & $19 \%$ \\
\hline 4 Autores & 1 & $13 \%$ & 1 & $9 \%$ & 0 & $0 \%$ & 2 & $10 \%$ \\
\hline TOTAL & 8 & $100 \%$ & 11 & $100 \%$ & 2 & $100 \%$ & 21 & $100 \%$ \\
\hline
\end{tabular}

Fonte: Movimento; RBCE; Pensar a Prática

Esses dados nos levam a considerar que a produção em torno da saúde na EF escolar tem se concentrado, na grande parte dos casos, em esforços individuais. Esse fato pode indicar que as energias dispensadas a tais estudos convergem de propostas isoladas. Os artigos assinados por três ou quatro 
autores, geralmente, apresentam desenhos metodológicos como propostas de intervenção e/ou levantamentos. Os estudos assinados por dois autores, tendem a se caracterizar pela relação orientando/orientador (frutos de Trabalhos de Conclusão de Curso de graduação e de dissertações e teses desenvolvidas em Programas de Pós-Graduação). Diante de tais observações, percebe-se a necessidade do aumento do esforço coletivo na produção de estudos. Tal aposta pode contribuir no compartilhamento coletivo de uma temática e, assim, contribuir para o aumento de pesquisadores sobre tal.

Sobre a tipologia dos artigos (gráfico 2), de acordo com as seções temáticas das revistas, a maioria dos estudos são identificados como "Artigo Original" (57\%) e os outros se distribuem ligeiramente pelas outras seções: Ensaio (9\%), Em Foco (10\%), Seção Temática (14\%), Resumos de Dissertações e Teses (5\%), Espaço Aberto (5\%). Este dado demonstra como os artigos originais podem ser considerados como uma expressiva contribuição para o crescimento do campo, pois derivam de pesquisas originais, em sua maioria, de campo/empíricas.

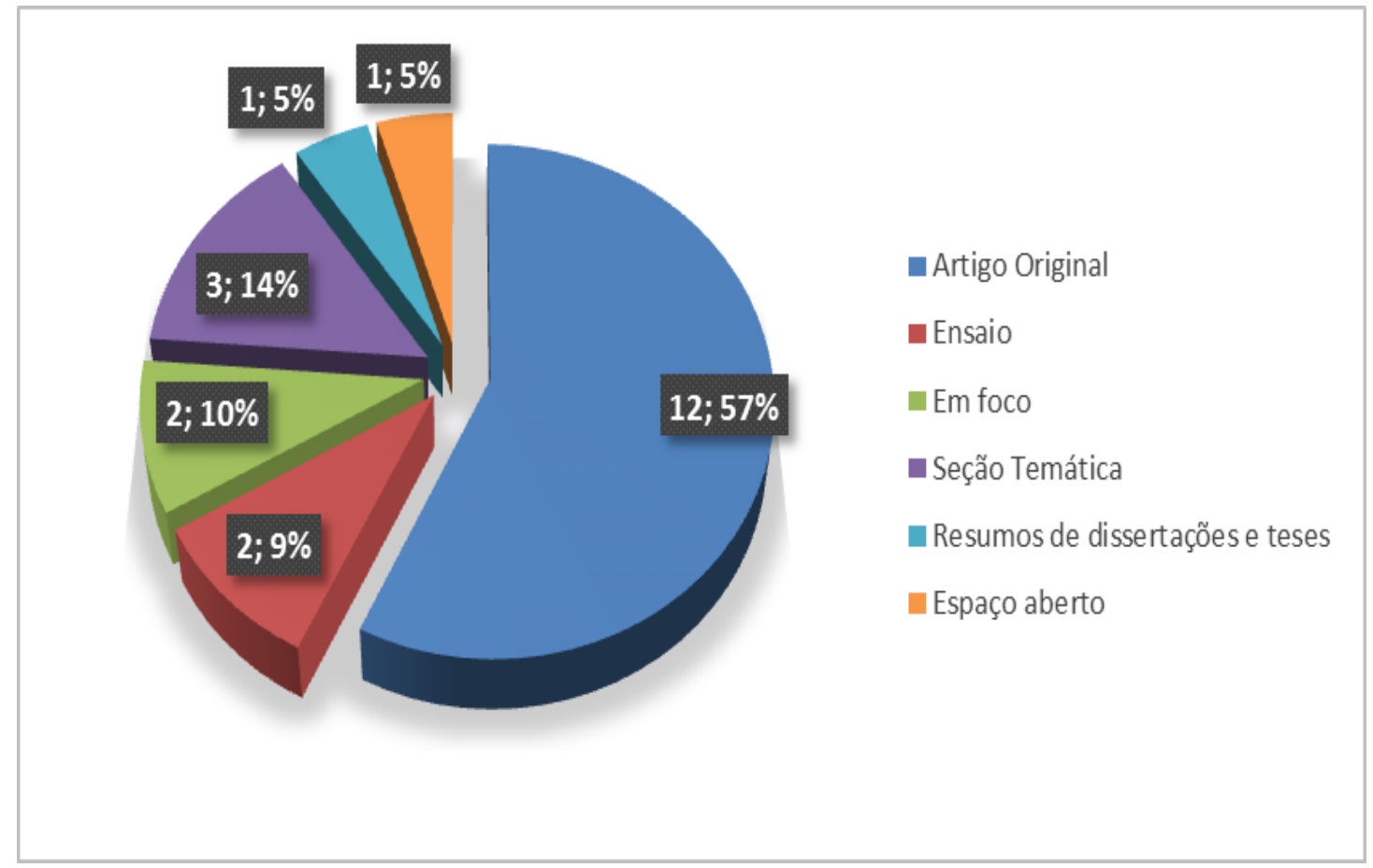

Figura 2 - Tipologia dos artigos. Fonte: Movimento, RBCE e Pensar a Prática.

Com respeito à titulação (gráfico 3), dos 40 (quarenta) autores que assinam os artigos analisados, nota-se que: $40 \%$ são doutores, $13 \%$ são mestres, $2 \%$ são especialistas e $7 \%$ são graduados. Tal dado nos permite a análise de que, grosso modo, os estudos desenvolvidos por doutores possuem maior profundidade e rigor, levando em consideração que um pesquisador nesse nível deverá possuir um maior aprofundamento teórico-metodológico e experiência. Também, vale ressaltar que $38 \%$ dos autores não foram 
identificados quanto a sua titulação, o que poderia mudar o sentido das análises nesse tópico 6 .

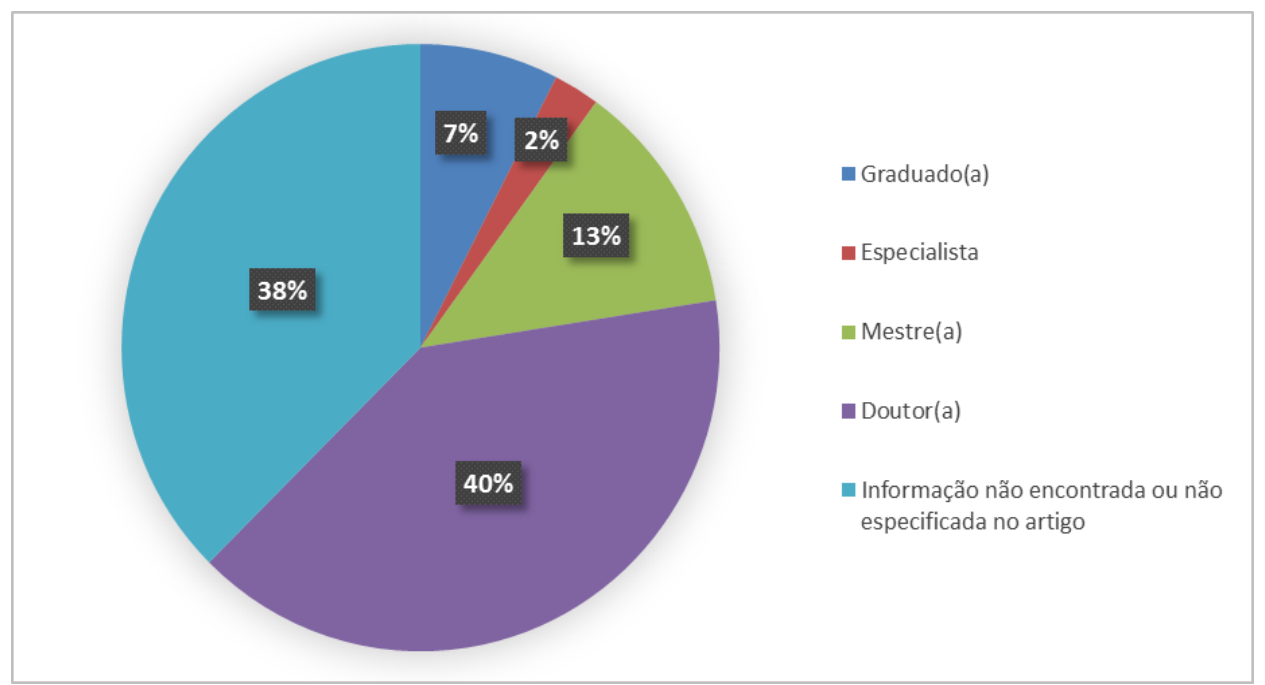

Figura 3 - Titulação dos autores. Fonte: Movimento, RBCE, Pensar a Prática.

Outro dado produzido em nosso levantamento consiste na distribuição dos autores por região. Os dados demonstram que 45\% provêm da região sudeste, $26 \%$ da região sul, $13 \%$ da região nordeste, $3 \%$ da região centro-oeste, $0 \%$ da região norte e $13 \%$ são autores de outros países (Espanha e Austrália). Aqui se percebe que a produção tem se concentrado nas regiões sudeste e sul, sendo que houve menor incidência de autores nas outras regiões. Tal disparidade é compreendida mediante o fato de que nas regiões sudeste e sul há uma maior consolidação de Programas de Pós-Graduação - lócus privilegiado da produção do conhecimento em nosso país.

É interessante notar que a Movimento apresentou autores de outros países ( $45 \%$ de incidência nessa revista, $13 \%$ da incidência total). Isso indica que este periódico tem se tornado referência internacional para publicação de autores na temática da saúde (na EF) escolar, talvez, pelo fato de seu estrato de classificação se apresentar o mais elevado entre as três revistas pesquisadas.

Com relação às instituições, dos 40 autores que assinaram os artigos, 28 (70\%) são de instituições públicas, $5(12,5 \%)$ são de instituições privadas, 4 (10\%) são de instituições de outros países e $3(7,5 \%)$ não foram informados. Outro resultado demonstra que desses mesmos 40 autores, 32 (80\%) são provenientes de Universidades, 5 (12,5\%) foram classificados como outros tipos de instituições (na maioria de escolas das redes públicas e/ou privadas) e os mesmos $3(7,5 \%)$, já citados anteriormente, não foram informados. Esses dados demonstram que: 1) a maioria dos autores possuem vínculo com instituições

6 Levamos em consideração a possibilidade de consultarmos a titulação dos autores através do acesso do seu currículo Lattes. Entretanto, descartamos essa ideia uma vez que nos interessava a titulação do autor declarada no momento da publicação do artigo. 
públicas; 2) é expressivo o número de autores provenientes de Universidades. Podemos atrelar esse resultado ao fato de que, no caso brasileiro, a produção do conhecimento se detém, majoritariamente, aos Programas de Pós-Graduação localizados nas Universidades públicas e particulares.

Este primeiro momento, indicou uma face descritiva sobre os números apresentados através da catalogação das revistas. Aqui, começamos a perceber um primeiro estado sobre o qual se encontra a produção em torno da temática da saúde na EF escolar nos três periódicos analisados. Na sequência, vamos realizar uma incursão de caráter mais qualitativa, procurando analisar os temas, desenhos teórico-metodológicos, principais discussões e conclusões, etc.

\section{A FACE QUALITATIVA DAS ANÁLISES}

Neste ponto propomos uma incursão reflexiva de modo a recuperar alguns dados já apresentados acima (na análise que se pautou mais descritiva), tanto quanto apresentamos outros que emergiram na análise qualitativa. Iniciamos expondo os temas discutidos nos 21 artigos.

É interessante notar que cinco artigos tratam da "ressignificação dos discursos acerca da saúde, da aptidão física e da relação entre essas duas". Dois procuram "ressignificar a própria EF escolar via programas de saúde/aptidão física". Um artigo apresenta um currículo australiano de EF em saúde. Quatro estudos tematizam a "escolarização da EF/ginástica, via as influências da higiene e suas repercussões para a saúde". Sete pesquisas se utilizam do ambiente escolar, de seus agentes e alunos(as) como fontes de dados: três tratam das percepções dos alunos sobre saúde, aptidão física, obesidade e beleza (feminina); dois se referem a aferição antropométrica de escolares (saúde, aptidão física e obesidade); um aborda as concepções dos professores de EF sobre saúde e EF escolar; um último que utiliza o espaço escolar no desenvolvimento e avaliação de um projeto de saúde ocular ${ }^{7}$. Ainda encontramos um artigo cuja temática é a presença da "EF em classe hospitalar". Outro artigo apresenta a relação da "causalidade esporte/atividade física/saúde".

Esses dados nos permitem uma aproximação com nossa hipótese inicial, que trata do embate de diferentes propostas e desenhos de estudos referentes à produção do tema da saúde na EF escolar. Ao observarmos as temáticas citadas acima, podemos dividi-las, grosso modo, em dois grandes agrupamentos (salientando que algumas temáticas poderão não se "afixar" em nenhum deles). De um lado, os estudos que buscam, em diferenciados aportes teórico-

\footnotetext{
7 Cabe ressaltar que esse foi o único artigo em que a EF escolar não foi tratada. Entretanto, fizemos questão de não excluí-lo da amostra pelo fato de que está publicado na RBCE, periódico fonte desta investigação.
} 
metodológicos, superar o discurso hegemônico (atividade física=saúde) vigente na EF (escolar). De outro, aqueles que utilizam esse discurso hegemônico para embasar, e fortalecer, suas pesquisas.

Tais questões também foram observadas por Bracht et al. (2012, p. 21) em seu estudo:

O mesmo se observa nas décadas de 1990 e 2000. Assim, se uma problematização foi feita envolvendo a relação entre a EF Escolar e sua fundamentação na perspectiva da promoção da saúde/AFRS [Atividade Física Relacionada à Saúde], indica-se a premência de se ampliar a compreensão da saúde além da dimensão biológica, incorporando outros fatores necessários à problematização desse complexo fenômeno. (inserto nosso).

Aqui dialogamos com Carvalho (2005), uma vez que nossos dados parecem coincidir com suas análises. Na esteira da autora, podemos explicar o fato dos estudos que buscam superar o discurso de que a atividade física gera saúde, mediante as características de seus autores que buscaram nas Ciências Sociais e Humanas as bases teórico-metodológicas para se contraporem a esse discurso dominante (CARVALHO, 2005). Tais bases permitem uma forte crítica a esse modelo de saúde como ausência de doença ou da obtenção de saúde (digase de passagem, biológica) via a mera exercitação corporal (relação causaefeito). Contudo, ainda concordamos com a autora, que a "outra ponta" não precisa ser desconsiderada, ou seja, é importante o diálogo entre as diferentes perspectivas que se dedicam a produzir o conhecimento dentro da área da EF (CARVALHO, 2005).

Aprofundando nossa análise, percebemos uma ampla variedade teóricometodológica nos artigos investigados. Os estudos dedicados à superação da noção "atividade física=saúde" tem forte base nos discursos da Promoção da Saúde numa vertente que considera os aspectos políticos, econômicos, sociais e culturais nas análises acerca do que seja ou venha a ser a saúde. Outras orientações seguem nos conceitos de qualidade de vida, modernidade/modernização, caráter multifatorial da saúde, educação para a saúde, etc. Algumas bases teóricas apresentadas foram os estudos de gênero, a sociologia da saúde, o pós-estruturalismo foucaultiano, o materialismo históricodialético, etc. Os desenhos metodológicos se dão pelos ensaios, narrativas, pesquisas de campo, etc.

Antes de prosseguirmos, é necessário abrirmos um parêntese para tratarmos de um fato um tanto curioso. Na face bibliométrica das análises foi observado que as políticas de seção das revistas apresentaram como maioria os Artigos Originais. Entretanto, de uma forma ambígua, alguns desses artigos "originais" são classificados por seus autores como ensaios (o que reconhecemos não retirar a sua originalidade). A partir do estudo de Bracht et al. (2011), 
podemos considerar que esses ensaios podem, também, ser considerados como estudos de fundamentação que segundo os autores:

São trabalhos que, mais do que esboçar um projeto de intervenção
- apesar de também o fazerem em algumas oportunidades -,
procuram, por meio de distintos referenciais, fornecer e/ou
problematizar as bases teóricas sobre as quais a prática
pedagógica dessa disciplina deve ser/é construída, assim como
questionar, além disso, aspectos fundantes de elementos que a
perpassam, por exemplo, os conteúdos de que trata. (BRACHT et
al., 2011, p. 15).

Esse é um movimento presente nos ensaios e demais artigos que procuram desmitificar a relação atividade física/saúde (CARVALHO, 2009). Desta forma, consideramos que os aportes teóricos são construídos no sentido de uma educação para a saúde, não no sentido de eliminar a esfera biológica, mas de ressignificá-la a partir de perspectivas pedagógicas (BRACHT, 2013). Tais estudos se aproximam de uma compreensão contextualizada da saúde, qual seja, aquela que se liga às pessoas e a partir das pessoas, colocando-as em movimento/processo em busca do bem-estar (DEJOURS, 1986).

Contudo, os estudos que possuem suas bases teórico-metodológicas nas Ciências Naturais apresentam uma concepção restrita de saúde, qual seja, aquela orientada nos princípios biofisiológicos. Seus desenhos são delineados a partir de estudos antropométricos, epidemiológicos, de base populacional onde se utiliza a análise estatística para aferir as relações causa-efeito. Esses artigos se limitam a uma "caricaturarização" da saúde em sua faceta restrita (biológica), pois, em muitos casos, desconsideram a complexidade que abrange tal conceito. Procuram, assim, determinar uma normalidade a partir da patologia, desconsiderando a pessoa que sente (experiência) - e que pode ser normativa de sua saúde (CANGUILHEM, 2009).

Quanto às conclusões apresentadas, podemos considerar que elas se referem, via de regra, aos objetivos apresentados em cada temática já referida. Por hora, destacamos aquelas consideradas principais: necessidade de posicionar a EF (escolar) como disciplina curricular/acadêmica e veículo da promoção da saúde; propor uma reorientação sobre o entendimento das relações entre EF/saúde/qualidade de vida; necessidade de superar o trato restrito (biológico) da saúde; superar as lacunas da Atividade Física Relacionada à Saúde deve-se ao considerar o caráter multifatorial da saúde (político, social, histórico, cultural, econômico, etc.); também sugere-se que programas direcionados à educação para a saúde não sejam apenas informativos em relação à adoção de hábitos saudáveis, mas também de como mantê-los.

A opção por dar visibilidade a essas conclusões centra-se na tese de que a saúde é para a EF uma questão pedagógica (BRACHT, 2013). Tais conclusões, sob a ótica da concepção de educação para a saúde apresentada por Kottmann e 
Küpper (1999), se ligam à proposta de que para se alcançar um fundamento que seja benéfico para a saúde é necessário que alunos e alunas tenham experiências positivas no campo do movimento e, também, possam construir competências e habilidades referentes à saúde nos planos individual-pessoal (aspectos das afecções psíquicas e biofisiológicas), social (aspectos da sociabilidade) e ecológico (aspectos relacionados ao meio ambiente).

Os estudos de Oliveira, Martins e Bracht (2015a; 2015b) demonstram como é possível a mudança nos projetos e práticas de professores de EF em relação à passagem de uma concepção restrita (biológica) de saúde para uma concepção ampliada (qual seja, aquela orientada nos princípios das Ciências Humanas e Sociais e da Saúde Coletiva). Os autores ainda sugerem que a saúde deve ser um tema da escola como um todo e que a EF irá contribuir a partir de sua especificidade - uma vez que os documentos oficiais, como os Parâmetros Curriculares Nacionais (PCN), orientam que a saúde escolar é um tema transversal (BRASIL, 1998).

\section{CONSIDERAÇÕES FINAIS}

O presente estudo nos possibilitou considerar que há um baixo "peso" da produção de artigos referentes ao tema da saúde na EF escolar. Tal fenômeno é incoerente se levarmos em consideração a própria constituição histórica da EF com a saúde, tanto quanto, a configuração social hodierna em que emergem programas e políticas em torno do tema saúde na escola. Isso nos parece ser um ponto crítico frente às demandas sociais promulgadas no atual contexto que solicitam, cada vez mais, uma contribuição da EF para o fortalecimento das ações de saúde nos ambientes educacionais. Entendemos ser necessário acumular conhecimentos sobre essa temática para que novas (e melhores) proposições da EF sobre as ações de educação para a saúde no espaço escolar sejam produzidas.

Percebemos que a maioria das produções vinculadas à temática da EF escolar e saúde nos periódicos investigados é fruto de ações individuais (quando não de um autor, de dois autores na relação orientador/orientando em que o estudo é conduzido sistematicamente pelo orientando). Consideramos ser necessária a constituição de grupos/coletivos de investigação em torno da temática o que pode ser profícuo na concentração de energias para estimular novos estudos que enfrentem os desafios da promoção da educação para a saúde nos espaços escolares através das ações da EF.

Constatamos uma ampla variedade teórico-metodológica nos artigos investigados. Grosso modo, há dois grandes movimentos dentro da produção referente ao nosso objeto de estudo. Um que procura reforçar o entendimento de 
saúde orientado nas Ciências Naturais e Biológica - o que se desdobra em estudos com enfoque biológico. O outro, procura nas Ciências Sociais e Humanas e na Saúde Coletiva superar a concepção restrita (biológica) de saúde, compreendendo-a em sua complexidade a partir das perspectivas sociais, histórica, cultural, política, econômica, etc. Entendemos que a emergência do segundo movimento (em torno das Ciências Sociais e Humanas e da Saúde Coletiva) permite a problematização de perspectivas tradicionais (biofisiológicas e biomédicas) até então hegemônicas no campo da EF.

No bojo da problematização proposta por parte dos artigos, é colocada a necessidade de reformulações em torno da relação EF e saúde no ambiente escolar com vista superar o trato restrito (biológico) conferido ao tema da saúde com ações em torno da consideração do seu caráter multifatorial. Podemos, então, considerar que a EF enquanto componente pedagógico tem como uma de suas funções sociais elencar a educação para a saúde no ambiente escolar - o que não se reduz apenas à exercitação corporal dos alunos. Essas considerações não pretendem excluir a esfera biológica da produção de saúde no contexto escolar. Ao contrário, é percebida a necessidade de ressignificar a vertente biológica à luz de novas possibilidades.

Por fim, reconhecemos os limites deste estudo, o qual se deteve em apenas três periódicos da EF brasileira. Até o presente, essa investigação expôs um levantamento parcial, diante de um universo de periódicos científicos da EF em âmbito nacional. Compreendemos que para realizar um estudo do estado da arte referente a presença do tema da saúde na EF escolar é necessário ampliar o número de periódicos investigados. Isso indica a necessidade do desenvolvimento de novas investigações com o objetivo de produzir novos dados e, assim, fortalecer o tema investigado.

\section{REFERÊNCIAS}

BRACHT, Valter. Educação Física e Saúde Coletiva: reflexões pedagógicas. In: FRAGA, Alex Branco; CARVALHO, Yara Maria; GOMES, Ivan Marcelo. As práticas corporais no campo da saúde. São Paulo: Hucitec, 2013.

BRACHT, Valter; FARIA, Bruno de Almeida; MORAES, Cláudia Emília Aguiar; ALMEIDA, Felipe Quintão de; GHIDETTI, Filipe Ferreira; GOMES, Ivan Marcelo; ROCHA, Maria Celeste; MACHADO, Thiago da Silva; ALMEIDA, Ueberson Ribeiro. A Educação Física Escolar como tema da produção do conhecimento nos periódicos da área no Brasil (19802010): parte I. Movimento, Porto Alegre, v. 17, n. 2, p. 11-34, 2011. Disponível em: https://seer.ufrgs.br/index.php/Movimento/article/view/19280.

BRACHT, Valter; FARIA, Bruno de Almeida; MORAES, Cláudia Emília Aguiar; FERNANDES, Erivelton; ALMEIDA, Felipe Quintão de; GHIDETTI, Filipe Ferreira; GOMES, Ivan Marcelo; ROCHA, Maria Celeste; MACHADO, Thiago da Silva; ALMEIDA, Ueberson Ribeiro; PENHA, Vinícius. A Educação Física Escolar como tema da produção do conhecimento nos 
periódicos da área no Brasil (1980-2010): parte II. Movimento, Porto Alegre, v. 18, n. 2, p.11-37, 2012. Disponível em: https://seer.ufrgs.br/Movimento/article/view/30158.

BRASIL. MINISTÉRIO DA EDUCAÇÃO. Parâmetros curriculares nacionais: terceiro e quarto ciclos do ensino fundamental: apresentação de temas transversais. Brasília: Ministério da Educação/ Secretaria de Ensino Fundamental, 1998.

BRASIL. MINISTÉRIO DA EDUCAÇÃO. MINISTÉRIO DA SAÚDE. Decreto Presidencial no 6.286, de 5 de dezembro de 2007. Institui o Programa Saúde na Escola - PSE, e dá outras providências. Diário Oficial da União, Brasília, 6 de dezembro de 2007. Seção 1, p. 2.

BRASIL. MINISTÉRIO DA SAÚDE. SECRETARIA DE ATENÇÃO À SAÚDE. DEPARTAMENTO DE ATENÇÃO BÁSICA. Instrutivo PSE. Brasília: Ministério da Saúde, 2011.

CANGUILHEM, Georges. O normal e o patológico. 6. ed. rev. Rio de Janeiro: Forense Universitária, 2009.

CARVALHO, Yara Maria. Entre o biológico e o social. Tensões no debate teórico acerca da saúde na Educação Física. Motrivivência, Florianópolis, ano XVII, n. 24, p. 97-105, 2005. Disponível em: https://periodicos.ufsc.br/index.php/motrivivencia/article/view/860.

CARVALHO, Yara Maria. O "mito" da atividade física e saúde. 4. ed. São Paulo: Hucitec, 2009.

DEJOURS, Christophe. Por um novo conceito de saúde. Revista Brasileira de Saúde Ocupacional, São Paulo, v. 14, n. 54, p. 7-11, 1986. Disponível em:

https://pt.scribd.com/document/237689633/TEXTO-DEJOURS-Por-Um-Novo-Conceitode-Saude.

GIL, Antônio Carlos. Como elaborar projetos de pesquisa. 4. ed. São Paulo: Atlas, 2008.

KIRK, David. Physical education futures. London: Routledge, 2010.

KOTTMANN, Lutz; KÜPPER, Doris. Gesundheitserziehung. In: GÜNZEL, Werner; LAGING, Ralf (Hersg.) (Band I). Neues Taschenbuch des Sportunterrichts; Grundlagen und pädagogisches Orientierungen. Baltmannsweliler: Schneider-Verl. Hohengehren. 1999, p. 235-252.

LUNARDI, Valéria Lerch. Problematizando conceitos de saúde, a partir do tema da governabilidade dos sujeitos. Revista Gaúcha de Enfermagem, Porto Alegre, v. 20, n. 1, p.26-40, 1999. Disponível em:

https://seer.ufrgs.br/RevistaGauchadeEnfermagem/article/view/4219.

MANOEL, Edison de Jesus; CARVALHO, Yara Maria. Pós-graduação na educação física brasileira: a atração (fatal) para a biodinâmica. Educação e Pesquisa, São Paulo, v. 37, n. 2, p. 389-406, 2011. Disponível em: http://www.scielo.br/scielo.php?pid=S1517$97022011000200012 \&$ script $=$ sci abstract\&tlng=pt.

OLIVEIRA, Amaurí Aparecido Bassoli. O tema saúde na Educação Física escolar: uma visão patogênica ou salutogênica? In: KUNZ, Elenor; HILDEBRANDT-STRAMANN, Reiner. (Org.). Intercâmbios científicos internacionais em Educação Física e esportes. Ijuí: Ed. Unijuí, 2004, p. 241-259.

OLIVEIRA, Victor José Machado; MARTINS, Izabella Rodrigues; BRACHT, Valter. Relações da educação física com o programa saúde na escola: visões dos professores das escolas 
de Vitória/ES. Pensar a Prática, Goiânia, v. 18, n. 3, p. 544-556, 2015a. Disponível em: https://www.revistas.ufg.br/fef/article/view/33028.

OLIVEIRA, Victor José Machado; MARTINS, Izabella Rodrigues; BRACHT, Valter. Projetos e práticas em educação para a saúde na educação física escolar: possibilidades! Revista da Educação Física/UEM, Maringá, v. 26, n. 2, p. 243-255, 2015b. Disponível em: http://www.periodicos.uem.br/ojs/index.php/RevEducFis/article/view/25600.

SANTOS, Boaventura de Souza. Um discurso sobre as ciências. 7. ed. São Paulo: Cortez, 2010. 